\title{
Guidelines: Usefulness and Limitations
}

\author{
Michael Gnant \\ Department of Surgery and Comprehensive Cancer Center, Medical University of Vienna, Austria
}

In this issue of BREAST CARE, the readership will find the most recent AGO (Arbeitsgemeinschaft Gynäkologische Onkologie; Gynaecological Oncology Group) guidelines both for the diagnosis and treatment of patients with early [1] and advanced/metastatic [2] breast cancer. Many clinicians in the field around the world have awaited this update of one of the most influential sets of recommendations for state-of-the-art treatments of breast cancer.

Since 2001, the AGO has built entity-specific committees in order to develop a comprehensive set of guidelines, in this case for breast cancer. What their Breast Committee of 44 experts in the field have worked out is not simply a compilation of the respective personal opinions, but a scientific effort to scrutinize recent publications and abstracts/presentations from major scientific meetings in order to identify potentially useful innovations in the care of breast cancer patients. As a result - and this is most commendable - the described treatment modalities are not only listed but also marked with their respective level of evidence [3], indicating the scientific maturity and readiness for implementation in our daily clinical practice.

This approach requires meticulous scientific analysis of innovative data presented in various formats, and is probably more labor than fun along the way. The authors and all coworkers should be rewarded by the thought that their efforts are multiplied by hundreds and thousands of colleagues in many countries who use the AGO guidelines to guide, discuss, and eventually define individual patient treatment strategies.

The US counterpart of the AGO guidelines can be found in the work of the National Comprehensive Cancer Network, NCCN (www.nccn.org). As our German colleagues, the NCCN aims at identifying the level of evidence for recommended treatments. In some details, comparison of these different guidelines gives interesting insights into mostly congruent but sometimes slightly differing conclusions for clinical practice. Such a comparison of several evidence-based sets of guidelines makes it very clear that there is no real objectivity - all these meritorious efforts occur in social, economic, and scientific environments, which are reflected in the results of such a process. I suggest that instead of claiming objectivity, we should realize that 'guidance' in the best sense of the word includes some range of interpretation - yet, still such a range can serve as most fruitful assistance in clinical decisionmaking. In addition to recommending treatments in given clinical situations, guidelines can be particularly helpful for 'not giving' treatments: especially in the field of early breast cancer, we face the problem of overtreatment for various reasons [4] - having clear-cut evidence based guidelines can be of great help in arguing a negative benefit/side effect assessment. The forensic significance of this aspect must not be underestimated.

The NCCN and AGO processes are entirely different from an opinion-based mechanism of defining treatment recommendations. Most prominently, the St. Gallen International Consensus Panel follows this approach: it meets biannually (next time in Vienna, March 18-21, 2015) in order to discuss potentially practice-changing developments in the treatment of breast cancer. That process is - consciously - not evidencebased; from the beginning the organizers wanted to include the interpretative power and judgment of decade-long practice experience of distinguished experts in addition to mere data depiction [5].

Both processes are important, but they must not be mixed up. For defining the optimal treatment of an individual patient, both approaches are needed. It is also important to mention that scientific considerations and practice recommendations must nowadays strictly adhere to rules of transparency and governance. In my view, the respective NCCN policies [6] can serve as a role model for this.

When applying guidelines to clinical practice, we must realize that it is of crucial importance to bear in mind the processes behind them and their respective individual methodological standards. As critically evaluated recently [7], some published guidelines are less than trustworthy - one needs to learn how to interpret methodological differences between them. This is particularly important nowadays where internet and social media based knowledge is easily accessible to patients and families, which in itself is great, but also bears the potential of dangerous confusion. The AGO guidelines published in this issue of BREAST CARE are exemplary for this important issue.

Another aspect in the creation of guidelines deserves mentioning: even in the industrialized world, we are facing increasing economic challenges in many areas of the health care

\section{KARGER}

Fax +497614520714

Information@Karger.com

www.karger.com (c) 2013 S. Karger GmbH, Freiburg

$1661-3791 / 13 / 0083-0172 \$ 38.00 / 0$

Accessible online at:

www.karger.com/brc
Prof. Dr. med. Michael Gnant

Medizinische Universität Wien

Universitätsklinik für Chirurgie

Währinger Gürtel 18-20, Wien 1090, Austria

michael.gnant@meduniwien.ac.at 
system [8]. Sometimes, these resource limitations and shortcomings have a tendency to drift into clinical practice guidelines. I do propose that such bias must be avoided when scientific guidelines are composed - there are other methods to assess this, and we should precisely differentiate between scientific data and health economy assessment related issues. After all, any reasonable public health assessment needs to start with an evidence based depiction of the benefits of a given treatment as defined by clinical trials.
Medicine is the 'applied science or practice of the diagnosis, treatment, and prevention of disease', as defined by the Oxford English dictionary [9]. Ultimately, this needs to be based on scientific evidence, and then transformed into something useful by the compassionate and experienced clinician. Both are equally needed for optimal patient care: knowledge and empathy. Reversing the process is dangerous, and must be outlawed by the medical community. Or in other words: The art of medicine begins where standards end.

\section{References}

1 Scharl A, Thomssen C, Harbeck N, et al.: AGO recommendations for diagnosis and treatment of patients with early breast cancer: update 2013. Breast Care 2013; DOI: 10.1159/000353617.

2 Harbeck N, Scharl A, Thomssen C, et al.: AGO recommendations for diagnosis and treatmen of patients with advanced and metastatic breast cancer: update 2013. Breast Care 2013; DOI: $10.1159 / 000353590$.
3 www.cebm.net

4 Gnant M, Steger G: Fighting overtreatment in adjuvant breast cancer therapy. Lancet 2009; 374:2029-2030.

5 Harbeck N, Thomssen C, Gnant M: St. Gallen 2013. brief preliminary summary of the consensus discussion. Breast Care 2013; 8:102-109.

6 http://www.nccn.org/about/disclosure.asp
7 Reames BN, Krell RW, Ponto SN, et al.: Critical evaluation of oncology clinical practice guidelines. J Clin Oncol 2013; DOI: 10.1200/JCO.2012.46.8371.

8 Sullivan R, Peppercorn J, Sikora K: Delivering affordable cancer care in high-income countries. Lancet Oncol 2011; 12: 933-980

9 Oxford English Dictionary,

http://oxforddictionaries.com/ 